\title{
АНАЛИЗ МНОГОЛЕТНИХ ЛЕСНЫХ ПОЖАРОВ ПО ФУНКЦИОНАЛЬНЫМ ЗОНАМ И ЛЕСНИЧЕСТВАМ
}

\author{
П.М. Мазуркин
}

\begin{abstract}
При этом эти зоны и лесничества принимаются как территориальные единицы и относительно них распределение лесных пожаров за многолетний период рассматривают дважды - по функциональным зонам и лесничествам. Показаны устойчивые закономерности распределения также дважды, причем ранжирование рейтинговых мест функциональных зон выполняют по росту антропогенной нагрузки на леса, а рейтинговые места лесничеств выполняют по увеличению количества лесных пожаров. Для повышения точности анализа принимаются данные о прошлых лесных пожарах за 25 лет и более.
\end{abstract}

Ключевые слова: лесные пожары, распределения, функциональные зоны, лесничества, закономерности.

Введение. Предлагаемый способ относится к лесному хозяйству, в частности, к предупреждающим системам тревожной сигнализации, отличающимся экстраполяцией или другими вычислениями, использующими скорректированные статистические данные о многолетней динамике лесных пожаров на территории одного лесного предприятия. Он может быть использован в условиях национальных парков, заповедников и других видов особо охраняемых территорий. Причем каждая особо охраняемая территория имеет разделение на функциональные зоны и лесничества.

Известен способ (ГОСТ Р 22.1.09-99. Безопасность в чрезвычайных ситуациях. Мониторинг и прогнозирование лесных пожаров. Общие требования) мониторинга и прогнозирования, включающий на местном и локальном уровнях общие требования по мониторингу и прогнозированию лесных пожаров и чрезвычайных лесопожарных ситуаций при ведении лесного хозяйства, а также контроль на локальном уровне (места лесных пожаров и площади, пройденные лесными пожарами) организацию работ по контролю за лесопожарной ситуацией и учету последствий лесных пожаров.

Недостатком является практическая невозможность использования статистических данных по многолетней динамике прошлых лесных пожаров для прогнозирования будущих ЧЛС по существующему территориальному разделению особо охраняемой территории на функциональные зоны и лесничества и тем самым отсутствие обратной связи для территориального планирования природоохранных мероприятий и мер по оперативному тушению потенциально возникающих лесных пожаров.

\footnotetext{
Мазуркин Петр Матвеевич,

доктор тех. наук, профессор,

Поволжский ГТУ,

e-mail: kaf_po@mail.ru
}

(C) Мазуркин П.М., 2014
Известен также способ физического анализа данных о статистической совокупности по текущим лесным пожарам и частично на малый период времени по прошлым на данный год лесным пожарам (Лесной дозор. URL: http://www.lesdozor.ru/ru/ sistemalesnoidozor/opisaniecomplecsa).

Физический анализ данных о лесных пожарах включает (в рамках объема притязаний предлагаемого способа выделены укрупненные действияпроцедуры) следующие отличительные признаки: 1) определение координат очага возгорания (максимальная ошибка определения координат очага возгорания - $250 \mathrm{M})$; 2) измерение радиуса обзора одной точки мониторинга до 30 км; 3) точность определения геодезического направления на очаг возгорания не менее $0.5^{\circ}$; 4) время для обзора одной точки - 10 мин; 5) интеграция и учет метеорологических данных; 6) интеграция и учет спутниковых данных; 7) интеграция данных из сторонних информационных систем; 8) возможность оперативного масштабирования и расширения системы для увеличения площади мониторинга; 9) неограниченное число пользователей с доступом к системе; 10) оперативное получение информации на мобильные устройства; 11) автоматическое обнаружение потенциально опасных объектов: дыма и пламени.

Главным недостатком является отсутствие учета условного расстояния до центров функциональных зон и лесничеств и экологических свойств лесных земельных участков по их пожарной опасности. В итоге не удается дополнительно проводить математический анализ многолетнего распределения численности лесных пожаров по функциональным зонам и лесничествам. Отсутствие физикоматематического анализа численности пожаров не дает прогнозировать вероятность появления лесных пожаров по функциональным зонам и лесничествам, что не позволяет осознано управлять технологической мощностью пожарных служб лесничеств.

Кроме того, отсутствие математического учета влияния функциональных зон и лесничеств на 
многолетнюю численность лесных пожаров не дает систематизировать весь накапливающийся массив количественной информации. Причем накопление информации можно было бы проводить по заранее и на долгое время установленному делению территории на функциональные зоны и лесничества. Затем по изменению значений каждого показателя многолетней совокупности лесных пожаров идентифицировать закономерности распределения количества лесных пожаров в зависимости от рангов по экологическому ранжированию функциональных зон и лесничеств. По выявленным закономерностям можно было бы выполнить ориентировочный инерционный прогноз на горизонт прогноза, равный основанию прогноза (промежутку времени от нуля до последнего измерения лесного пожара), а также рабочий инерционный прогноз на одну треть периода измерений.

Технический результат - повышение функциональных возможностей физико-математического анализа многолетней численности лесных пожаров, а также точности инерционного прогнозирования лесных пожаров в будущем, выявлением устойчивых трендов по распределениям лесных пожаров по функциональным зонам и лесничествам.

Этот технический результат достигается тем, что способ анализа многолетних лесных пожаров по функциональным зонам и лесничествам, включающий измерение радиуса обзора одной точки мониторинга до 30 км и интеграцию данных из сторонних информационных систем, проведение физического анализа данных о текущих лесных пожарах, отличающиийся тем, что для проведения физикоматематического анализа принимаются данные о прошлых лесных пожарах на данной территории не менее чем за пять лет, функциональные зоны и лесничества принимаются как территориальные единицы и относительно них на данной территории распределение лесных пожаров за многолетний период в прошлом рассматривают дважды - по функциональным зонам и лесничествам, а затем по многолетним данным выявляют устойчивые закономерности распределения также дважды, причем ранжирование рейтинговых мест функциональных зон выполняют по росту антропогенной нагрузки на леса, а рейтинговые места лесничеств выполняют по увеличению количества лесных пожаров, после этого устанавливают длительность позиционирования системы слежения за лесными пожарами на радиусе линии обзора мониторинга лесных пожаров в зависимости от распределения количества прошлых лесных пожаров по функциональным зонам и лесничествам.

Для повышения точности [1-10] физикоматематического анализа принимаются данные о прошлых лесных пожарах за 25 лет и более.

За начало распределение принимают момент времени образования постоянной структуры функциональных зон и лесничеств на данной территории, например, особо охраняемой территории в виде национального парка, при этом за точки мониторинга дважды принимают функциональную зону или лесничество, причем эти точки мониторинга принимают постоянными по площади с координатами в виде постоянных азимутов и радиусов расположения относительно радарной системы «Дозор», у которого конструктивно выполняют возможность управления длительностью времени позиционирования на заданном радиусе в зависимости от закономерности распределения прошлых лесных пожаров, затем слежение за новыми лесными пожарами проводят с учетом длительности наблюдения за теми зонами и лесничествами в виде точек мониторинга, на которых в прошлом за учтенный период времени произошло большее количество лесных пожаров.

В системе «Дозор» предусматривают измерение радиуса обзора одной точки мониторинга до 30 км с возможностью функционального расширения этой технической функции за счет учета распределения многолетних лесных пожаров в прошлом периоде времени по функциональным зонам и лесничествам при автоматизированном обходе радиуса обзора по тем точкам, которые имели в прошлом наибольшее количество пожаров, при этом время обхода радиуса обзора будет переменной физической величиной, зависящей от закономерностей распределения лесных пожаров в прошлом по территории функциональных зон и лесничеств, что позволяет принять функциональные зоны и лесничества при физическом анализе и математическом прогнозировании лесных пожаров как физикоматематические единицы точек мониторинга за лесными пожарами.

Сущность технического решения заключается в том, что функциональные зоны и лесничества принимаются как территориальные единицы и относительно них на данной территории распределение лесных пожаров за многолетний период в прошлом рассматривается дважды - по функциональным зонам и лесничествам. Это позволяет учесть при территориальном планировании чрезвычайных пожароопасных ситуаций на будущее вывяленные закономерности распределения.

Сущность технического решения заключается также в том, что в системе «Дозор» предусматривается измерение радиуса обзора одной точки мониторинга до 30 км, поэтому появляется возможность функционального расширения этой технической функции за счет учета распределения многолетних лесных пожаров по функциональным зонам и лесничествам при автоматизированном обходе радиуса обзора по тем точкам, которые имели в прошлом наибольшее количество пожаров. Тогда время обхода радиуса обзора будет переменной физической величиной, зависящей от закономерностей распределения лесных пожаров в прошлом по территории.

Положительный эффект достигается тем, что функциональные зоны и лесничества учитывают при физическом анализе и прогнозировании лесных пожаров как физико-математические единицы. 
Новизна технического решения заключается в том, что впервые ранжирование рейтинговых мест $i$ функциональных зон было выполнено изначально по росту антропогенной нагрузки. А список лесничеств заполняется по алфавиту, поэтому рейтинговые места $j$ нами были даны по увеличению количества лесных пожаров. Таким образом, влияющая переменная $i$ задана изначально по росту антропогенной нагрузки и она пригодна для любых территорий, а влияющая переменная $j$ была по росту числа пожаров за многолетний период и поэтому она пригодна только для локальных территорий лесных предприятий. Поэтому ранжирование по параметру $j$ зависит от конкретной лесной территории. В зависимости от распределения количества лесных пожаров по функциональным зонам и лесничествам, имеющим постоянные азимуты и радиусы расположения относительно радарной системы «Дозор», появляется возможность управления длительностью времени позиционирования. Иначе говоря, слежение за новыми лесными пожарами проводится с учетом длительности наблюдения за теми зонами и лесничествами, на которых в прошлом произошли большее количество лесных пожаров.

Способ анализа многолетних лесных пожаров по функциональным зонам и лесничествам, например для особо охраняемой территории в виде национального парка, выполняется следующим образом.

Вначале выясняют по журналу учета лесных пожаров промежуток времени, за который структура функциональных зон и лесничеств не менялась. Начало периода распределения принимают с момента изменения структуры территориального управления национальным парком, а за конец периода принимают последний текущий год до момента распределения. После этого из журнала учета лесных пожаров выписывают по всем многолетним данным, количества лесных пожаров, происшедших на каждой функциональной зоне и лесничестве и по этим исходным данным составляют таблицу с ранжированием мест. При этом по столбцам располагают функциональные зоны и общую сумму лесных пожаров по всем функциональным зонам с их рейтинговыми местами. При большом количестве лесничеств на данной территории по строкам таблицы располагают лесничества по алфавиту с указанием отдельного столбца рейтингового места лесничества.

Для проведения физико-математического анализа принимаются данные о прошлых лесных пожарах на данной территории не менее чем за пять лет, функциональные зоны и лесничества принимаются как территориальные единицы и относительно них на данной территории распределение лесных пожаров за многолетний период в прошлом рассматривают дважды - по функциональным зонам и лесничествам, а затем по многолетним данным выявляют устойчивые закономерности распределения также дважды, причем ранжирование рейтинговых мест функциональных зон выполняют по росту антропогенной нагрузки на леса, а рейтинговые места лесничеств выполняют по увеличению количества лесных пожаров, после этого устанавливают длительность позиционирования системы слежения за лесными пожарами на радиусе линии обзора мониторинга лесных пожаров в зависимости от распределения количества прошлых лесных пожаров по функциональным зонам и лесничествам.

Для повышения точности физикоматематического анализа принимаются данные о прошлых лесных пожарах за 25 лет и более.

За начало распределение принимают момент времени образования постоянной структуры функциональных зон и лесничеств на данной территории, например, особо охраняемой территории в виде национального парка, при этом за точки мониторинга дважды принимают функциональную зону или лесничество, причем эти точки мониторинга принимают постоянными по площади с координатами в виде постоянных азимутов и радиусов расположения относительно радарной системы «Дозор», у которого конструктивно выполняют возможность управления длительностью времени позиционирования на заданном радиусе в зависимости от закономерности распределения прошлых лесных пожаров, затем слежение за новыми лесными пожарами проводят с учетом длительности наблюдения за теми зонами и лесничествами в виде точек мониторинга, на которых в прошлом за учтенный период времени произошло большее количество лесных пожаров.

В системе «Дозор» предусматривают измерение радиуса обзора одной точки мониторинга до 30 км с возможностью функционального расширения этой технической функции за счет учета распределения многолетних лесных пожаров в прошлом периоде времени по функциональным зонам и лесничествам при автоматизированном обходе радиуса обзора по тем точкам, которые имели в прошлом наибольшее количество пожаров, при этом время обхода радиуса обзора будет переменной физической величиной, зависящей от закономерностей распределения лесных пожаров в прошлом по территории функциональных зон и лесничеств, что позволяет принять функциональные зоны и лесничества при физическом анализе и математическом прогнозировании лесных пожаров как физикоматематические единицы точек мониторинга за лесными пожарами.

Пример реализации способа. Государственный природный Национальный парк «Марий Чодра» организован 1 декабря 1985 года. Марий Чодра, в переводе, означает «марийский лес». И назван он так не случайно - вся территория парка покрыта прекрасными сосновыми борами и хвойношироколиственными лесами.

Парк находится на юго-востоке республики, в трех административных районах - Моркинском, Звениговском, Волжском - в 20-40 км от г. Волжска и 50-70 км от столицы Республики Марий Эл г. Йошкар-Олы. 
Регистрация пожаров. В таблице 1 приведено количество пожаров с учетом распределения их количества за 23 года по функциональным зонам и лесничествам. До 1987 года распределение лесничеств и их лесных кварталов было иным.

Таблица 1

Динамика лесных пожаров на территории национального парка «Марий Чодра» за 1987-2009 гг., ШШт.

\begin{tabular}{|c|c|c|c|c|c|c|c|}
\hline \multirow{3}{*}{$\begin{array}{c}\text { Наименова- } \\
\text { ние } \\
\text { лесничества } \\
\text { (по алфавиту) }\end{array}$} & \multirow{3}{*}{$\begin{array}{c}\mathrm{Mec} \\
-\mathrm{TO} \\
j\end{array}$} & \multicolumn{5}{|c|}{ Функциональные зоны с местами $i$} & \multirow{3}{*}{$\begin{array}{c}\text { Кол- } \\
\text { во } \\
\text { пожа- } \\
\text { ров } \\
N_{j}, \\
\text { шт. }\end{array}$} \\
\hline & & \begin{tabular}{|c|} 
запо- \\
вед- \\
ный \\
режим \\
\end{tabular} & $\begin{array}{c}\text { особо } \\
\text { охра- } \\
\text { ня- } \\
\text { емая } \\
\end{array}$ & $\begin{array}{l}\text { экстен- } \\
\text { сивной } \\
\text { рекреа- } \\
\text { ции } \\
\end{array}$ & $\begin{array}{c}\text { интен- } \\
\text { сивной } \\
\text { рекреа- } \\
\text { ции } \\
\end{array}$ & $\begin{array}{c}\text { хо- } \\
\text { зяйств. } \\
\text { назнач. }\end{array}$ & \\
\hline & & 1 & 2 & 3 & 4 & 5 & \\
\hline Лушмарское & 3 & 0 & 7 & 17 & 37 & 4 & 65 \\
\hline Керебелякск. & 1 & 5 & 0 & 2 & 0 & 0 & 7 \\
\hline $\begin{array}{l}\text { Кленово- } \\
\text { горск. }\end{array}$ & 2 & 1 & 5 & 14 & 23 & 9 & 52 \\
\hline Яльчинское & 4 & 0 & 2 & 27 & 100 & 13 & $\begin{array}{c}14 \\
2 \\
\end{array}$ \\
\hline Всего по парку & y $N_{i}$ & 6 & 14 & 60 & 160 & 26 & 266 \\
\hline
\end{tabular}

Книга учета лесных пожаров ФГБУ «Национальный парк «Марий Чодра» представляет собой

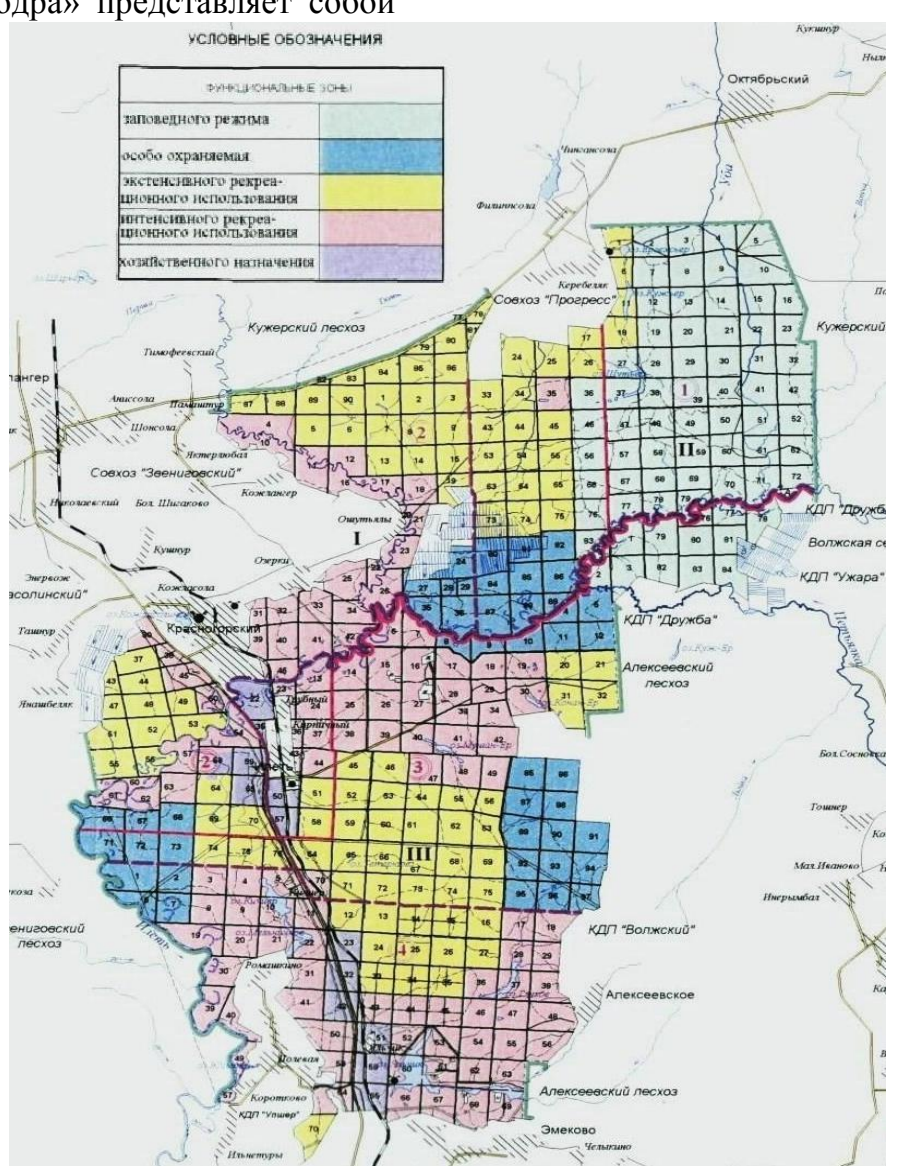

Puc. 1. Карта-схема территории национального парка «Марий Чодра» с разделением на функииональные зоны и лесные квартала

Территория Национального парка разделена на 5 функциональных зон: зона заповедного режима (7590 га), особо охраняемая зона (4772 га), зона экстенсивной рекреации (11248 га), зона интенсивной рекреации (12039 га), зона хозяйственного назначения (1226 га). Наибольшее количество пожаров на- журнал, в котором составитель акта о пожаре (старший инженер ОЗЛ, начальник ПХС, лесничий, помощник лесничего, мастер леса) парка или лесничества, где произошло возгорание, записывает все известные ему данные о возгорании.

Ранжирование рейтинговых мест $i$ функциональных зон было выполнено изначально по росту антропогенной нагрузки. А список лесничеств заполняется по алфавиту, поэтому рейтинговые места $j$ нами были даны по увеличению количества лесных пожаров. Таким образом, влияющая переменная $i$ задана изначально по росту антропогенной нагрузки, а влияющая переменная $j$ была по росту числа пожаров за многолетний период. Поэтому ранжирование по параметру $j$ зависит от конкретной лесной территории.

Динамика лесных пожаров по функциональным зонам. На рисунке 1 показана карта с нанесенными на нее функциональными зонами в ФГУ «Национальный парк «Марий Чодра». Всего выделены четыре зоны. 
ления туда запрещен, и все возгорания были от грозовой деятельности.

На пространственном графике (рис. 2) четко просматривается влияние обоих рейтинговых мест $i$ и $j$ на распределение лесных пожаров за многолетний период.

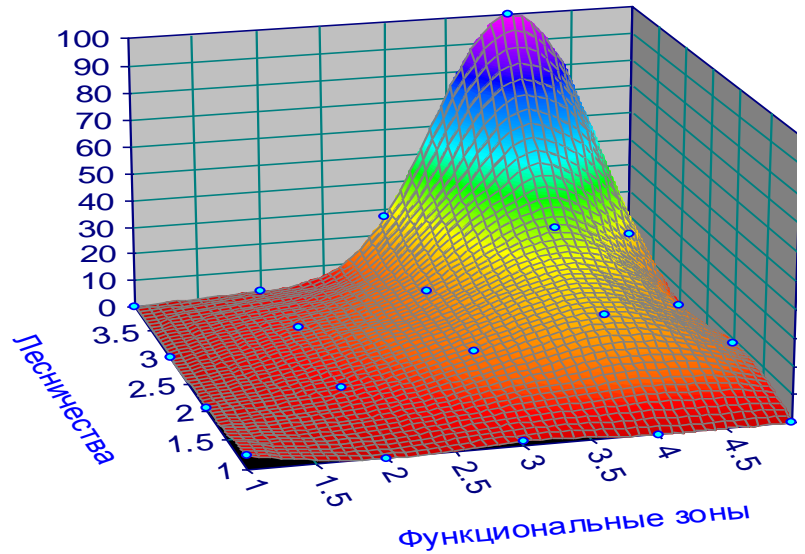

Puc. 2. Пространственный график изменения общей численности лесных пожаров за 1982-2009 г2. в зависимости от рейтинговых мест функииональных зон и лесничеств

Общая модель распределения количества всех пожаров по функциональным зонам (последняя строка таблицы 1) характеризуется (рис. 3) двухчленным уравнением

$$
\begin{gathered}
N_{i}=6,50859 \exp (0,27909 i)+ \\
+2,21723 i^{164,4702} \exp (-46,17848 i)
\end{gathered}
$$

где $N_{i}$ - количество лесных пожаров всего, шт., $i$ рейтинговое место функциональной зоны.

Наибольшее количество пожаров в целом по парку наблюдается в промежутке $i$ от трех до четыpex. Место 3 соответствует зоне экстенсивной рек-

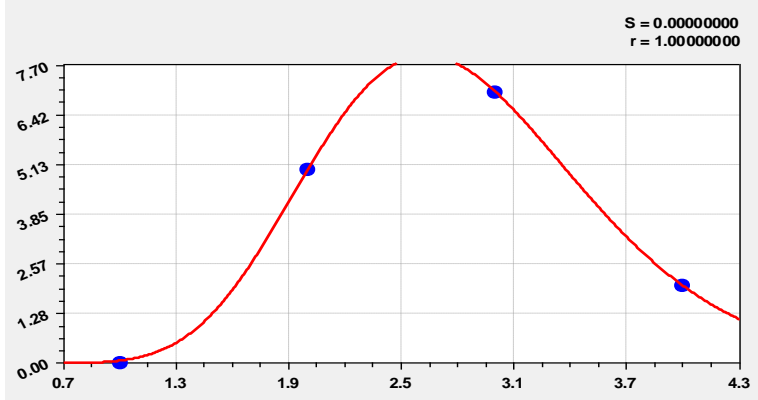

Распределения пожаров по особо охраняемой зоне

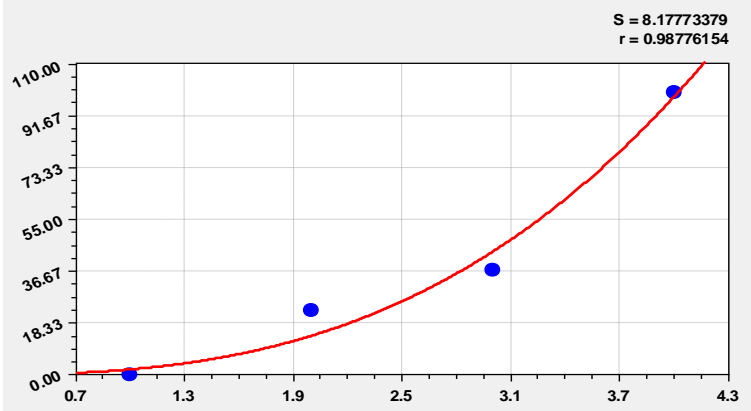

Распределения пожаров по зоне интенсивной рекреачии реации (60 пожаров), а точка 4 - зоне интенсивной рекреации (160 шт.).

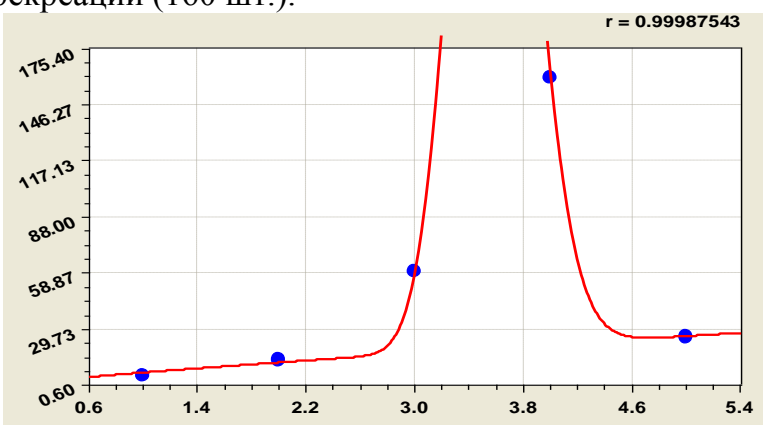

Распределение пожаров по функциональным зонам

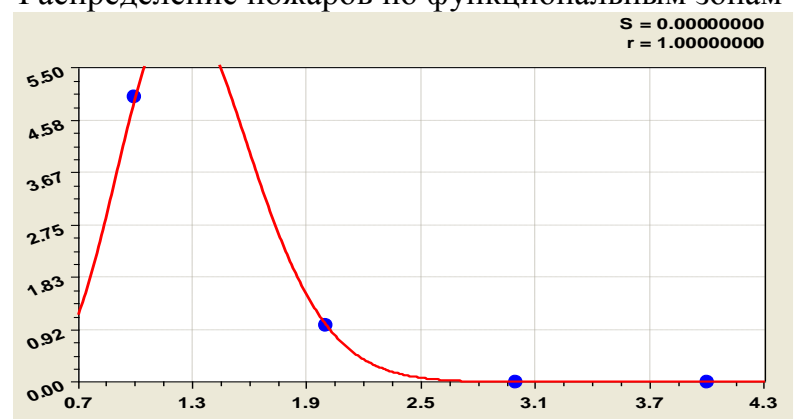

Распределения пожаров по заповедному режиму

Рис. 3. График распределения многолетних лесных пожаров

Наименьшее количество пожаров наблюдается в зоне заповедного режима (6 шт.).

По отдельным функциональным зонам, в зависимости от рейтингового места $j$ лесничества, графики изменения численности лесных пожаров даны на рисунке 4.

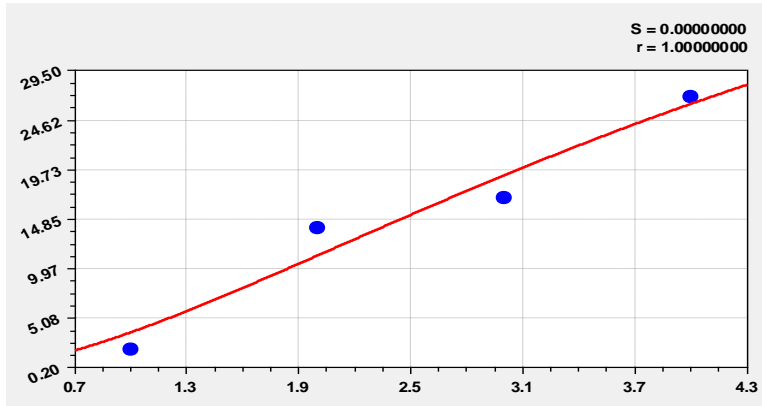

Распределения пожаров по зоне экстенсивной рекреации $\begin{aligned} S & =4.46358795 \\ r & =0.76759609\end{aligned}$

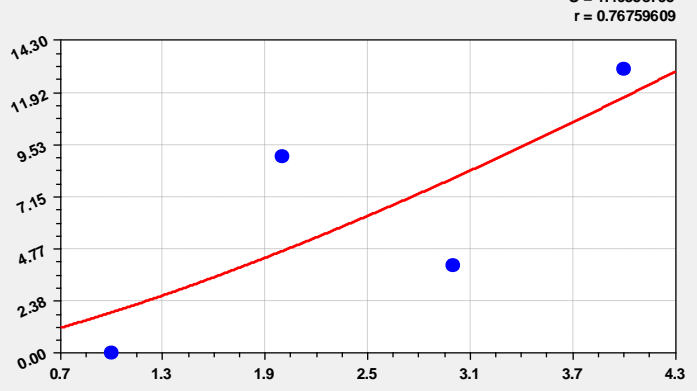

Распределения пожаров по зоне хозяйственного назначения

Рис. 4. График распределения многолетних лесных пожаров по четырем функциональным зонам территории заповедника 


\section{в зависимости от рейтинговых мест лесничеств}

Распределение лесных пожаров по лесничествам. Национальный парк поделен на 4 лесничества: Керебелякское, Лушкарское, Кленовогорское, Яльчинское. Самое большое по площади лесничество - Кленовогорское, его площадь 10397 га. Площадь Керебелякского лесничества составляет 9888 га, Лушмарского - 8885 га, Яльчинского - 7705 га.

На рисунке 5 изображены границы четырех лесничеств национального парка.
В целом по всем функциональным зонам распределение лесничеств по количеству пожаров подчиняется (рис. 6) формуле

$$
N_{j}=10,06720 j^{1,88425}
$$

где $N_{j}$ - количество лесных пожаров по всем функциональным зонам, шт., $j$ - рейтинговое место лесничества.

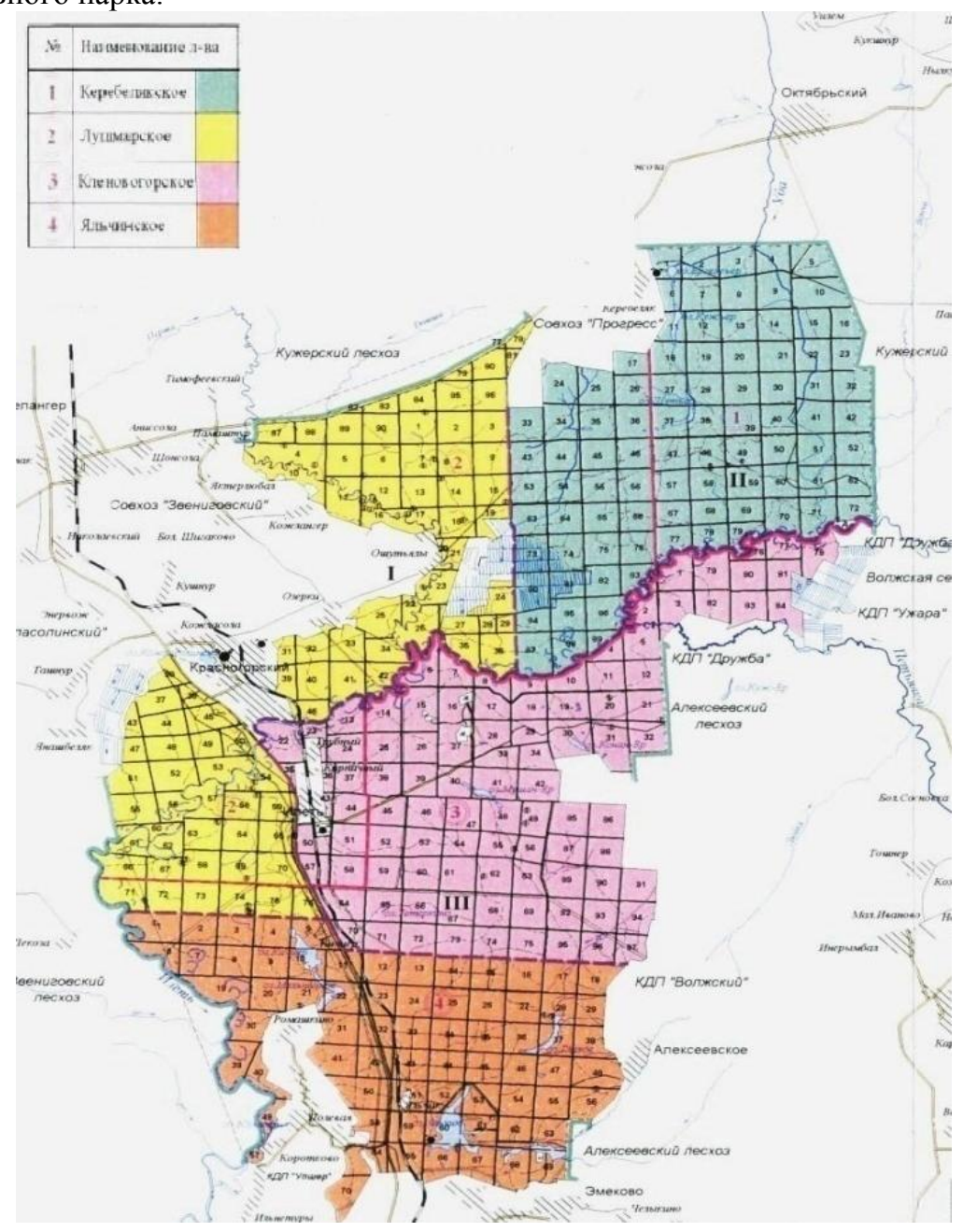

Pис. 5. Карта-схема административного распределения лесничеств в ФГУ «Начиональный парк «Марий Чодра» без учета рейтинговых мест

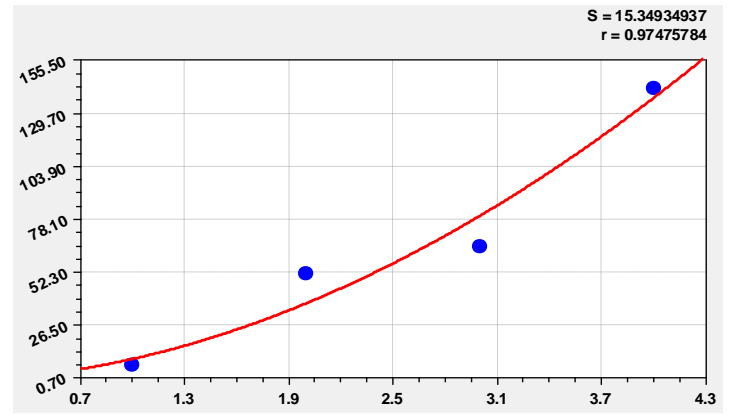

Pис. 6. График распределения общеей численности лесных пожаров за 1982-2009 г2. по лесничествам с учетом их рейтинговых мест
Заметно, что остатки после формулы имеют волновой характер. Это видно по отклонениям на рисунке 6 точек относительно среднестатистической линии. Поэтому, при количестве лесничеств более 7, возможна идентификация и волновых составляющих общей закономерности.Распределение лесных пожаров за период 1987-2009 гг. по отдельным лесничествам показано на рисунке 7 .

Заключение. Предлагаемый способ обладает простотой реализации, так как по фактическим прошлым многолетним данным о лесных пожарах на конкретной территории остается необходимо из алфавитного списка лесных предприятий (лесни- 
честв) вначале располагать по рейтингу возрастания количества лесных пожаров, а затем провести физико-математический анализ статистической выборки по типу таблицы 1.

Применение предложенного способа расширяет возможности территориального экологического

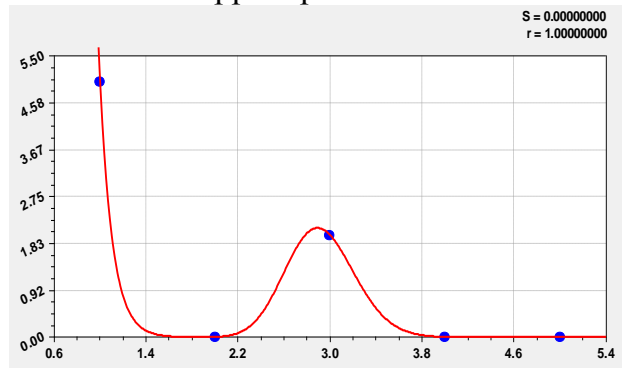

Пожары в Керебелякском лесничестве

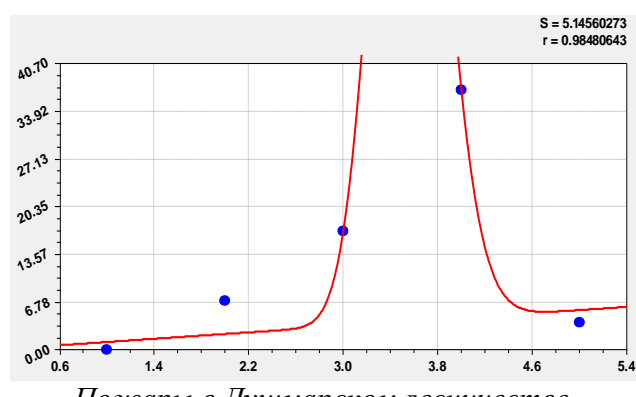

Пожары в Лушмарском лесничестве мониторинга, повышает функциональные возможности системы типа «Лесной Дозор» физический отличительный признак «измерение радиуса обзора одной точки мониторинга до 30 км».

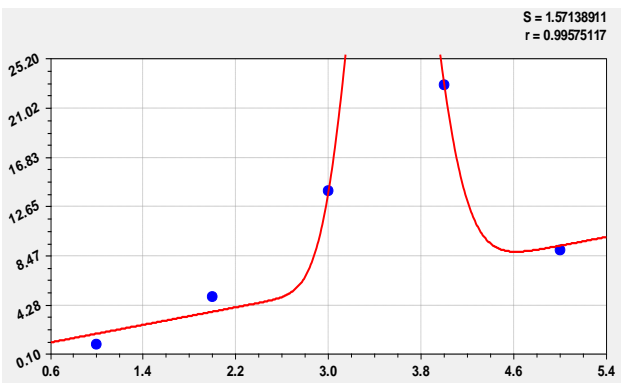

Пожары в Кленовогорском лесничестве

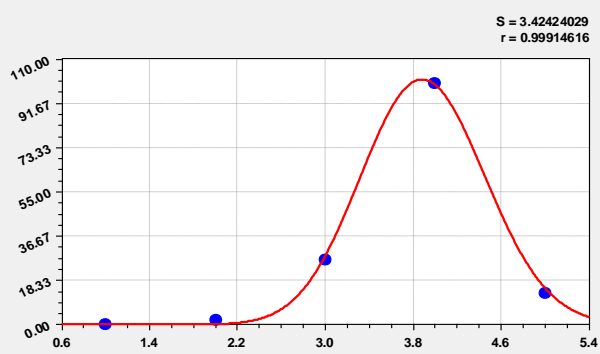

Пожары в Яльчикском лесничестве

Рис. 7. График распределения общей численности лесных пожаров за 1982-2009 г2. по каждому из четырех лесничеств в зависимости от рейтингового места функииональной зонь

В итоге появляется практическая возможность, с использованием многолетних данных о лесных пожарах на территории, экологического и технологического (пожаротушения) мониторинга для

\section{Библиографический список}

1. Мазуркин, П.М., Блинова, К.С. Активность Солнца и годичная динамика лесных пожаров на особо охраняемой территории / П.М. Мазуркин, К.С. Блинова // Успехи современного естествознания. - 2013.- N 1. - С.102-107.

2. Мазуркин, П.М. Асимметричные вейвлет-сигналы многолетней динамики численности лесных пожаров Республики Марий Эл / П.М. Мазуркин, К.С. Блинова, А.В. Хазиев // Вестник Казанского технол. ун-та.- 2013. - Т. 16. - N 15. - С.148151.

3. Мазуркин, П.М., Каткова, Т.Е. Моделирование многолетней динамики изменения площади лесных пожаров / П.М. Мазуркин, Т.Е. Каткова // Вестник Воронежского института ГПС МЧС России. - 2013. - N1 (6). - С.31-37.

4. Мазуркин, П.М., Каткова, Т.Е. Анализ многолетней динамики удельной площади лесных пожаров / П.М. Мазуркин, Т.Е. Каткова // Вестник Воронежского института ГПС МЧС России. 2013. №2 (7). С.37-43.

5. Мазуркин, П.М., Каткова, Т.Е. Вейвлет-анализ многолетней динамики локальной численности лесных пожаров / П.М. Мазуркин, Т.Е. Каткова // Современные проблемы науки и образования. - 2013. - N 5 - [электронный ресурс] URL: http://www.science-education.ru/111-10164 (дата обращения: 26.09.2013).

6. Мазуркин, П.М., Скорикова, Л.А. Динамика темпе- прогнозирования и уточнения распределения лесных пожаров вдоль радиуса обзора, а также провести прогнозный расчет по ним значений параметров будущих лесных пожаров.

\section{References}

1. Mazurkin, P.M., Blinova, K.S. Aktivnost Solntsa i godichnaya dinamika lesnyih pozharov na osobo oh-ranyaemoy territorii / P.M. Mazurkin, K.S. Blinova // Us-pehi sovremennogo estestvoznaniya. - 2013.- N 1. - S.102-107.

2. Mazurkin, P.M. Asimmetrichnyie veyvlet-signalyi mnogoletney dinamiki chislennosti lesnyih pozharov Res-publiki Mariy El / P.M. Mazurkin, K.S. Blinova, A.V. Haziev // Vestnik Kazanskogo tehnol. un-ta.- 2013. - T. 16. - N 15. - S.148-151.

3. Mazurkin, P.M., Katkova, T.E. Modelirovanie mnogoletney dinamiki izmeneniya ploschadi lesnyih pozharov / P.M. Mazurkin, T.E. Katkova // Vestnik Voronezhskogo instituta GPS MChS Rossii. - 2013. - N1 (6). - S.31-37.

4. Mazurkin, P.M., Katkova, T.E. Analiz mnogolet-ney dinamiki udelnoy ploschadi lesnyih pozharov / P.M. Mazurkin, T.E. Katkova // Vestnik Voronezhskogo instituta GPS MChS Rossii. 2013. №2 (7). S.37-43.

5. Mazurkin, P.M., Katkova, T.E. Veyvlet-analiz mnogoletney dinamiki lokalnoy chislennosti lesnyih po-zharov / P.M. Mazurkin, T.E. Katkova // Sovremennyie pro-blemyi nauki i obrazovaniya. - 2013. - N 5 - [elektronnyiy resurs] - URL: http://www.science-education.ru/111-10164 (data obrascheniya: 26.09.2013)

6. Mazurkin, P.M., Skorikova, L.A. Dinamika temperaturyi goreniya drevesnyih opilok pri ispyitanii szhiganiem 
ратуры горения древесных опилок при испытании сжиганием / П.М. Мазуркин, Л.А. Скорикова // Вестник КНИТУ. - 2011. - N 7. - C.58-61.

7. Мазуркин, П.М., Филонов, А.С. Математическое моделирование. Идентификация однофакторных статистических закономерностей: учеб. пособие / П.М. Мазуркин, А.С. Филонова. - Йошкар-Ола: МарГТУ, 2006. - 292 с.

8. Пат. 2406079 Российская Федерация, МПК G 01 N 25/00, G 01 N 33/46 (2006.01). Способ испытания древесных материалов по температуре сгорания / Мазуркин П.М., Кудрявцева Л.А. (РФ); заявитель и патентообладатель Марийский гос. тех. ун-т. - N 2009133872/28; заявл. 09.09.2009; опубл. 10.12.2010.

9. Пат. 2449272 Российская Федерация, МПК G 01 N 33/46, А 01 G 23/00 (2006.01). Способ испытания древесных материалов на горючесть / Мазуркин П.М., Кудрявцева Л.А.; заявитель и патентообладатель Марийский гос. тех. ун-т. - N 2009133878/15; заявл. 09.09.2009; опубл. 27.04.2012; Бюл. N 12.

10. Пат. 2416793 Российская Федерация, МПК G 01 N 33/46, А 62 C 3/02 (2006.01). Способ испытания лесных горючих материалов на воспламеняемость / Мазуркин П.М., Кудрявцева Л.А., Егорова Е.А. (РФ); заявитель и патентообладатель Марийский гос. тех. ун-т. - N 2009133875/12; заявл. 09.09.2009; опубл. 20.04.2011.
/ P.M. Mazurkin, L.A. Skorikova // Vestnik KNITU. - 2011. - N 7. - S.58-61.

7. Mazurkin, P.M., Filonov, A.S. Matematicheskoe modelirovanie. Identifikatsiya odnofaktornyih statisti-cheskih zakonomernostey: ucheb. posobie / P.M. Mazurkin, A.S. Filonova. - Yoshkar-Ola: MarGTU, 2006. - 292 s.

8. Pat. 2406079 Rossiyskaya Federatsiya, MPK G $01 \mathrm{~N}$ 25/00, G 01 N 33/46 (2006.01). Sposob ispyitaniya drevesnyih materialov po temperature sgoraniya / Mazurkin P.M., Kudryavtseva L.A. (RF); zayavitel i patentoobladatel Mariy-skiy gos. teh. un-t. - N 2009133872/28; zayavl. 09.09.2009; opubl. 10.12.2010.

9. Pat. 2449272 Rossiyskaya Federatsiya, MPK G $01 \mathrm{~N}$ 33/46, A 01 G 23/00 (2006.01). Sposob ispyitaniya drevesnyih materialov na goryuchest / Mazurkin P.M., Kudryavtseva L.A.; zayavitel i patentoobladatel Mariyskiy gos. teh. un-t. - N 2009133878/15; zayavl. 09.09.2009; opubl. 27.04.2012; Byul. N 12.

10. Pat. 2416793 Rossiyskaya Federatsiya, MPK G $01 \mathrm{~N}$ 33/46, A 62 S 3/02 (2006.01). Sposob ispyitaniya lesnyih goryuchih materialov na vosplamenyaemost / Mazurkin P.M., Kudryav-tseva L.A., Egorova E.A. (RF); zayavitel i patentoobladatel Mariyskiy gos. teh. un-t. - N 2009133875/12; zayavl. 09.09.2009; opubl. 20.04.2011

\title{
ANALYSIS OF LONG-TERM FOREST FIRES BY FUNCTIONAL AREAS AND FORESTRY
}

\section{Mazurkin P.M.}

Volga State University of Technology; Ioshkar-Ola, Russia

\begin{abstract}
Thus these zones and forestry are accepted as territorial units and concerning them distribution of forest fires for the long-term period consider twice - on functional zones and forestry. Steady regularities of distribution also are shown twice, and ranging of rating places of functional zones carry out on growth of anthropogenic load of the woods, and rating places of forestry carry out on increase in number of forest fires. For increase of accuracy of the analysis data on last forest fires in 25 years and more are accepted.
\end{abstract}

Keywords: forest fires, distributions, functional zones, forestry, regularities. 